\title{
Pristimerin inhibits the proliferation of HT1080 fibrosarcoma cells by inducing apoptosis
}

\author{
DAICHI HAYASHI ${ }^{1}$, TOSHIHARU SHIRAI ${ }^{1}$, RYU TERAUCHI $^{1}$, SHINJI TSUCHIDA ${ }^{1}$, \\ NAOKI MIZOSHIRI $^{1}$, YUKI MORI ${ }^{1}$, YUJI ARAI ${ }^{2}$, OSAM MAZDA $^{3}$ and TOSHIKAZU KUBO $^{1}$ \\ ${ }^{1}$ Department of Orthopedics, Graduate School of Medical Science; Departments of ${ }^{2}$ Sports and Parasports \\ Medicine, and ${ }^{3}$ Immunology, Kyoto Prefectural University of Medicine, Kyoto 602-8566, Japan
}

Received May 24, 2019; Accepted September 6, 2019

DOI: $10.3892 / 01.2020 .11405$

\begin{abstract}
Fibrosarcoma is a soft tissue sarcoma that is classified as a rare cancer. Therefore, no standard anti-tumor drug therapy has been established for fibrosarcoma. Although pristimerin (PM) has been reported to exert an anti-tumor effect on various types of cancer, no studies have examined the therapeutic effect of PM on soft tissue sarcoma. The purpose of the current study was to investigate the anti-tumor effect of PM on human fibrosarcoma cells (HT1080). The present study examined the cell viability, IC50 values and ability to induce apoptosis of PM in HT1080 and normal human dermal fibroblast (aHDF) cells. The effect of PM on the following signaling pathways associated with cell proliferation was also evaluated: AKT and mitogen-activated protein kinase (MAPK). Using mice subcutaneously transplanted with fibrosarcoma cells, the effect of PM treatment was investigated on tumor growth inhibition, body weight and liver and renal function. The results revealed that PM administration reduced cell viability and induced apoptosis in a dose-dependent matter. In HT1080 cells, the IC50 value of PM was $0.16 \mu \mathrm{M}$ at $24 \mathrm{~h}$ and $0.13 \mu \mathrm{M}$ at $48 \mathrm{~h}$. PM treatment also decreased the levels of phosphorylated AKT, mTOR, NF- $\mathrm{KB}$ and phosphorylated ERK in a dose-dependent manner. In the PM injection group, the increase in tumor volume was significantly reduced and the effect on weight loss and liver and renal function were revealed to be insignificant. PM exerted little effect on normal
\end{abstract}

Correspondence to: Professor Toshiharu Shirai, Department of Orthopedics, Graduate School of Medical Science, Kyoto Prefectural University of Medicine, 465 Kajii-cho, Kawaramachi Street, Kamigyo-ku, Kyoto 602-8566, Japan

E-mail: shi-ra-e@koto.kpu-m.ac.jp

Abbreviations: IC50, 50\% inhibitory concentration; PI3K, phosphoinositide 3-kinase; mTOR, mammalian target of rapamycin; $\mathrm{NF}-\kappa \mathrm{B}$, nuclear factor- $\mathrm{B}$; MAPK, mitogen-activated protein kinase; ERK, extracellular signal-regulated kinase; JNK, c-Jun N-terminal kinase; TBST, tris-buffered saline tablets; JSPS, Japan Society for the Promotion of Science

Key words: pristimerin, fibrosarcoma, caspase, apoptosis, proliferation, AKT, mitogen-activated protein kinase human dermal fibroblasts and was highly effective against human fibrosarcoma cells. The results indicated that PM may be used as a potential therapeutic agent against fibrosarcoma.

\section{Introduction}

Soft tissue sarcoma is a solid tumor that constitutes less than $1 \%$ of all malignancies. On an average, 3 out of every 100,000 people suffer from soft tissue sarcoma, making it a rare disease (1). Molecular classification based on the genetic alteration divides sarcomas into two main categories: i) sarcomas with specific genetic alterations; and ii) sarcomas displaying multiple, complex karyotypic abnormalities with no specific pattern (2). The main anticancer drugs used to treat their sarcoma are doxorubicin and ifosfamide (3), but the success rate of therapy using these drugs is approximately $25 \%(4,5)$. The incidence of fibrosarcomas among soft tissue sarcomas is approximately 2-3\% (6), and it is considered to be a tumor that does not respond easily to anticancer drugs. Therefore, there is an urgent need of development of novel drugs that are effective against fibrosarcoma.

Anticancer drugs derived from natural organic compounds extracted from plants and marine products have gained widespread attention in the recent years. Eribulin and Trabectedin have been used in the clinic since 2010, and have been reported to be effective on soft tissue sarcomas (7). Pristimerin (PM) is a terpenoid extracted from the Celastraceae family of plants (Fig. 1A). Terpenoids have anti-inflammatory and anti-tumor effects (8-11), and PM has been reported to show anti-inflammatory and antioxidant effects $(12,13)$. In addition, PM has been reported to have anti-tumor effects on lung cancer, breast cancer, prostate cancer, uterine cancer, gliomas, and leukemias (14-18). Docetaxel, another commonly used terpenoid, has demonstrated efficacy against soft tissue sarcomas and is used clinically (19). However, there are still no reports on the use of PM. PM is a terpenoid like docetaxel, but its molecular weight $(465 \mathrm{kDa})$ is lower than that of docetaxel $(808 \mathrm{kDa})$, and it is believed to have higher cell penetration ability (20). The purpose of this study was to clarify if PM is an effective drug against fibrosarcoma.

\section{Materials and methods}

Cell lines and cell conditions. The human fibrosarcoma cell line, HT1080 (cat. no. 300216-SF), and aHDF cells (normal 
human dermal fibroblasts) were purchased from Cosmo Bio Co., Ltd. Dulbecco's modified Eagle's medium (DMEM) was purchased from Nacalai Tesque. The cells were incubated in complete DMEM containing $10 \%$ fetal bovine serum (FBS; Equitech-Bio), 100 units/ml penicillin, and $100 \mathrm{mg} / \mathrm{ml}$ streptomycin (complete DMEM; Nacalai Tesque) at $37^{\circ} \mathrm{C}$ in a humidified atmosphere containing $5 \% \mathrm{CO}_{2}$. Cells were trypsinized with trypsin/ethylenediaminetetraacetic acid (Nacalai Tesque) and subcultured.

Reagents. PM was purchased from Sigma-Aldrich; Merck $\mathrm{KGaA}$, dissolved in dimethyl sulfoxide (Nacalai Tesque) to yield a $10 \mathrm{mM}$ stock solution, and stored at $-20^{\circ} \mathrm{C}$. PM was diluted to the required concentrations in cell culture medium.

Antibodies. Primary antibodies against AKT (cat. no. 4691S), p-AKT (cat. no. 9271T), BAX (cat. no. 2772T), BCL-2 (cat. no. 2872T), mTOR (cat. no. 2983S), p-mTOR

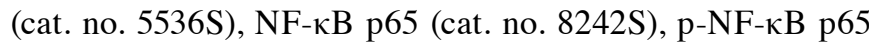
(cat. no. 3033S), JNK (cat. no. 9252S), p-JNK (cat. no. 9251S), ERK (cat. no. 9102S), p-ERK (cat. no. 9101S), and $\beta$-actin (cat. no. A2228), and anti-mouse IgG, and anti-rabbit IgG secondary antibodies were purchased from Cell Signaling Technology.

Cell viability assay. Cell viability was determined using the RealTime-Glo MT Cell Viability Assay kit (Promega Corporation). Cells were seeded in a Poly-1-Lysine(PLL)-coated 96-well plate at a density of $1 \times 10^{3}$ cells/well in $100 \mu$ l complete DMEM. After 24 h, MT cell viability substrate and Nanoluc ${ }^{\circledR}$ enzyme were added to the medium, and the cells were treated with various concentrations of PM. The CentroXS3 LB 960 System (Berthold Technologies) was used to measure light emission 12, 24 and $48 \mathrm{~h}$ after PM treatment. The IC50 was calculated as the concentration of the drug that reduced cell viability by $50 \%$ under experimental conditions.

Apoptosis analysis. Cells were seeded in a 12-well plate at a density of $1 \times 10^{4}$ cells/well in $1 \mathrm{ml}$ complete DMEM. Cells were harvested following treatment with PM for $24 \mathrm{~h}$, and stained with $1 \mu \mathrm{l}$ Annexin V-FITC and $0.5 \mu \mathrm{l}$ PI solution (Nacalai Tesque) for $20 \mathrm{~min}$ at room temperature in dark. Following incubation, binding buffer was added and the cells were analyzed by flow cytometry using a FACS Vantage Flow Cytometer (BD Biosciences). For analysis of each sample, 10,000 events were recorded.

Western blot analysis. Cells were seeded in a 6-well plate at a density of $1 \times 10^{5}$ cells/well in $2 \mathrm{ml}$ complete DMEM. Cells were harvested by scraping using $150 \mu \mathrm{l}$ of radio-immunoprecipitation assay buffer supplemented with protease and phosphatase inhibitor cocktails (Sigma-Aldrich; Merck KGaA) and solubilization was achieved by $10 \mathrm{~min}$. The samples were centrifuged at $15,000 \mathrm{x}$ g for $10 \mathrm{~min}$ and the supernatant was aspirated. Protein concentration was estimated using bicinchoninic acid (BCA) assay, and equal amounts of total proteins were loaded onto polyacrylamide gels for sodium dodecyl sulfate polyacrylamide gel electrophoresis (PAGE). Samples containing $10 \mu \mathrm{g}$ of protein were separated on $10 \%$ Bis-Tris Gel NuPAGE ${ }^{\circledR}$ electrophoresis using 5\% MOPS SDS Running
Buffer (Thermo Fisher Scientific, Inc.). Separated proteins were dry-blotted onto nitrocellulose iBlot ${ }^{\circledR}$ gel transfer stacks in iBlot Gel transfer devices (Thermo Fisher Scientific, Inc.) for $7 \mathrm{~min}$. Nitrocellulose membrane was blocked by shaking in Blocking One solution (Nacalai Tesque) for $60 \mathrm{~min}$ at room temperature. The blots were subsequently incubated overnight at $4^{\circ} \mathrm{C}$ in the same solution containing the following primary antibodies (1:4,000 dilutions each). $\beta$-actin was used as the loading control. Blots probed for $\beta$-actin and other primary antibodies were washed thrice with TBST and incubated for $60 \mathrm{~min}$ at room temperature with peroxidase-conjugated secondary antibodies in 1:4,000 dilutions. The blots were again washed thrice with TBST, and chemiluminescent signal was visualized using Chemi Lumi One imager (Nacalai Tesque). Protein band intensities were assessed using the ECL Select LAS500 reagent (GE Healthcare).

Animals. Animal experiments were approved by the Experimental Animals Committee, Kyoto Prefectural University of Medicine. BALB/C-nu/nu mice (age 4 weeks, females) were purchased from Shimizu Laboratory Supplies. All procedures were undertaken in accordance with the NIH Guide for the Care and Use of Laboratory Animals.

In vivo tumor growth assay. After acclimatization of mice to laboratory conditions for 1 week, cells $\left(1.0 \times 10^{7}\right)$ resuspended in $100 \mu \mathrm{l}$ phosphate-buffered saline were injected into the hypodermis of the back of each mouse under $5 \%$ isoflurane anesthesia. After tumors grew to approximately $100 \mathrm{~mm}^{3}$, the mice were injected intraperitoneally (i.p.) with PM at the dose of $1 \mathrm{mg} / \mathrm{kg}$, every three days for 15 days. Untreated mice (10\% DMSO and 90\% PBS i.p) were used as controls (each group contained 4 mice). Tumor size was measured with a vernier caliper (calculated volume $=$ shortest diameter $^{2} \mathrm{x}$ longest diameter/2) after every 3 days. All the mice were sacrificed by cervical dislocation under 5\% isoflurane inhalation anesthesia without causing pain, and the tumors were weighed on day 15 . Liver and renal toxicity were examined by blood sampling and liver and renal enzyme assays on day 15.

Statistical analysis. All experimental data are represented as means \pm SD. Parametric one-way analysis of variance (ANOVA) was used to examine statistical differences among the groups. If the result was significant, the Tukey-Kramer test was used to determine specific differences between the groups. In all analyses, $\mathrm{P}<0.05$ was considered to indicate a statistically significant difference.

\section{Results}

PM treatment inhibits the proliferation of HT1080 cells. In order to study the anti-tumor effect of PM, cell viability was measured at 12, 24 and $48 \mathrm{~h}$ after PM administration (0, 0.1, $0.25,0.5$ and $1 \mu \mathrm{M})$. As shown in Fig. 1B, higher concentrations of PM $(0.5$ and $1 \mu \mathrm{M})$ significantly suppressed the viability of aHDF cells at 12 and $24 \mathrm{~h}$. Moreover, the viability of aHDF cells was observed to significantly lower after $48 \mathrm{~h}$ of PM administration. Meanwhile, PM treatment reduced the viability of HT1080 cells in a concentration-dependent manner at all the measured time points. In addition, the IC50 values of 
A

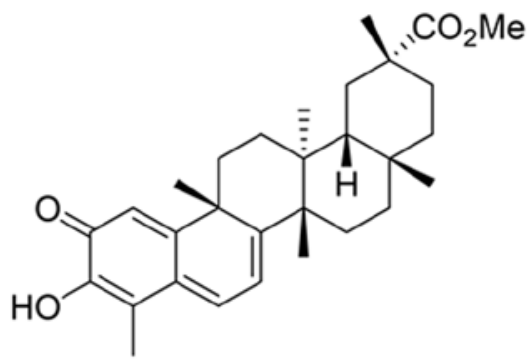

B

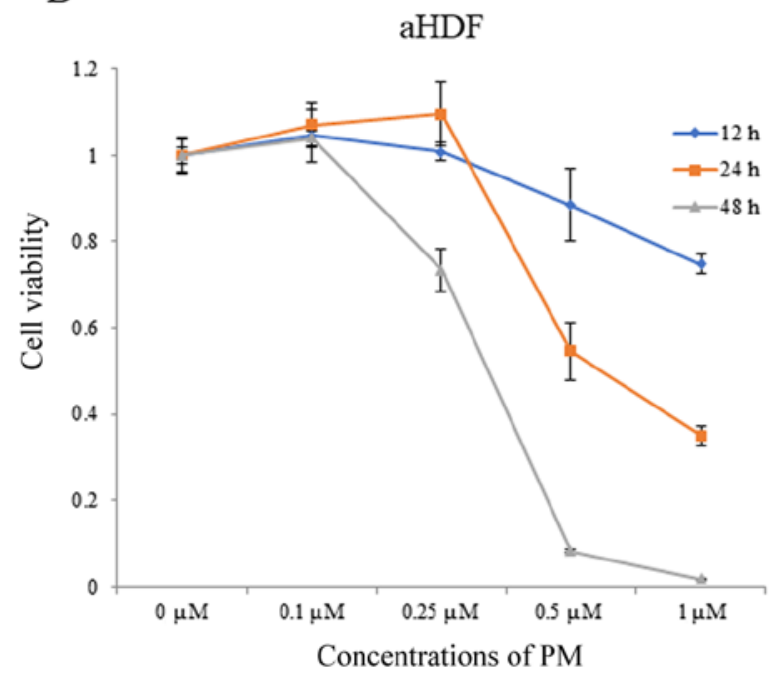

HT1080

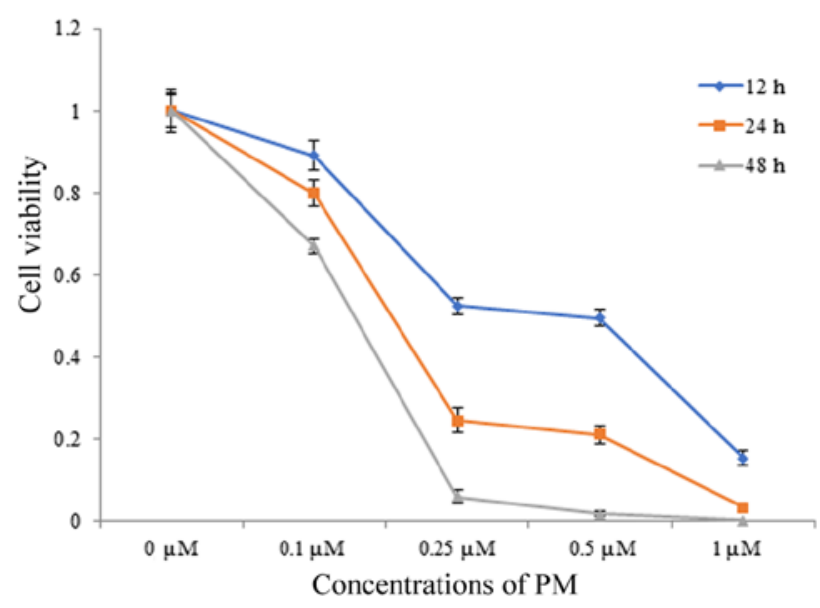

Figure 1. Structure of PM and effect of PM on the viability of fibrosarcoma. (A) Structural formula of PM. (B) aHDF and HT1080 cells were treated with various doses $(0-1 \mu \mathrm{M})$ of PM for 12, 24 and $48 \mathrm{~h}$. Cell viability was assessed using the Real Time-Glo MT cell Viability assay (n=4). PM, pristimerin.

$\mathrm{PM}$ in aHDF cells after 12, 24 and $48 \mathrm{~h}$ of PM administration was $1 \mu \mathrm{M}$ or higher, $0.59 \pm 0.04$ and $0.32 \pm 0.02 \mu \mathrm{M}$, respectively. Meanwhile, the IC50 values of PM in HT1080 cells were $0.43 \pm 0.10,0.16 \pm 0.01$ and $0.13 \pm 0.01 \mu \mathrm{M}$, respectively.

PM induces apoptosis in HT1080 cells. In order examine the effect of PM on induction of apoptosis in HT1080 cells; the number of apoptotic cells was analyzed by flow cytometry after 24 and $48 \mathrm{~h}$ of PM administration. As shown in Fig. 2A and B, PM treatment increased the percentage of early apoptotic in HT1080 cells in a concentration and time-dependent manner. However, no significant apoptosis was induced in cells at the concentrations $\leq 0.1 \mu \mathrm{M}$.

PM induces apoptosis by activation of caspases. In order to investigate if PM administration induced apoptosis via activation of caspases, we performed a caspase-3 assay. As shown in Fig. 2C, PM administration exhibited a concentration increase in caspase-3 activity after $6 \mathrm{~h}$ of treatment. Furthermore, western blot analysis was performed to evaluate the expression of apoptosis-related proteins. As shown in Fig. 2D, treatment with PM increased the levels of phosphorylated JNK in a concentration-dependent manner. Moreover, PM administration decreased the expression of BCL-2, an apoptosis inhibiting factor, and increased the expression of BAX, an apoptosis promoting factor.

PM inhibits cell proliferation by inhibition of AKT and MAPK signaling. The correlation between PM treatment and AKT pathway [AKT (cell survival signaling), mTOR, NF-кB] and the MAPK pathway (ERK) was evaluated by western blot analysis. PM treatment decreased the levels of phosphorylated $\mathrm{p}-\mathrm{AKT}, \mathrm{p}-\mathrm{NF}-\kappa \mathrm{B}$, and p-mTOR in a concentration-dependent manner. Further, PM administration decreased the phosphorylation of ERK, which is involved in cell proliferation in a concentration-dependent manner (Fig. 3).

PM inhibits the proliferation of tumor cells in vivo. Mice were injected with subcutaneous grafts comprising human fibrosarcoma cells, and the effect of PM administration was analyzed. As shown in Fig. 4A and B, increase in tumor volume was significantly reduced in the PM dose group as compared to the control group. The increase in tumor volume was significantly inhibited after 3 days of PM administration. Meanwhile, a significant difference in body weight of the mice was observed in the PM group immediately after PM administration, as compared to the control group, but no significant difference was observed after 15 days of PM treatment. In an arterial blood draw, aspartate transferase (AST) and alanine transferase (ALT) values, indicators of hepatic impairment, were comparable in both the control group and PM dose group. blood urea nitrogen (BUN) and creatinine clearance (Cre) values, indicators of renal function, were also normal in both groups.

\section{Discussion}

Fibrosarcoma is frequently difficult to treat because of its poor sensitivity to anticancer drugs. Therefore, the development 
A

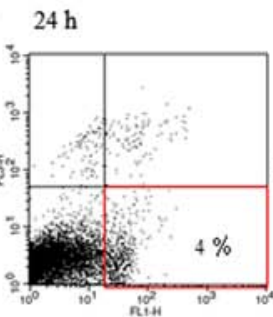

B

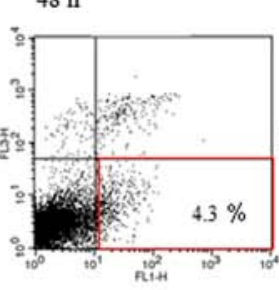

PM: $0 \mu \mathrm{M}$

C

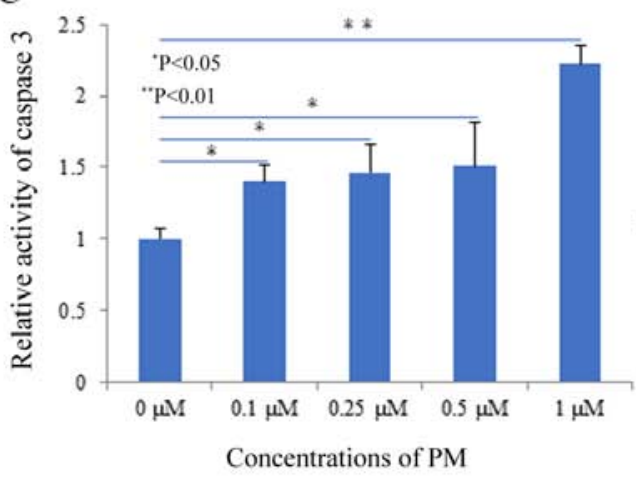

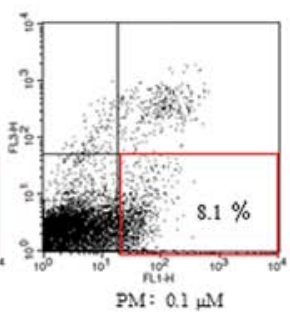

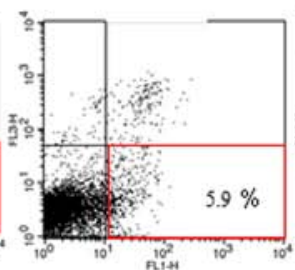

$\mathrm{PM}: 0.1 \mu \mathrm{M}$
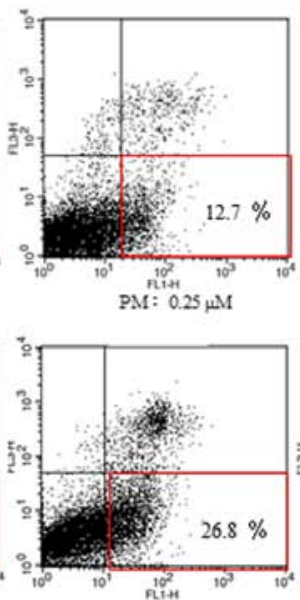

PM: $0.25 \mu \mathrm{M}$

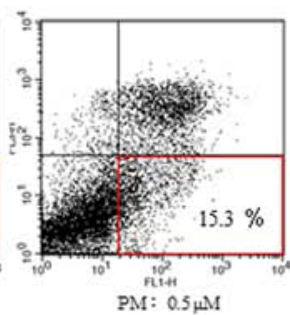

$\mathrm{PM}: 0.5 \mu \mathrm{M}$

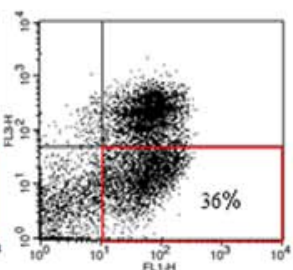

$\mathrm{PM}: 0.5 \mu \mathrm{M}$
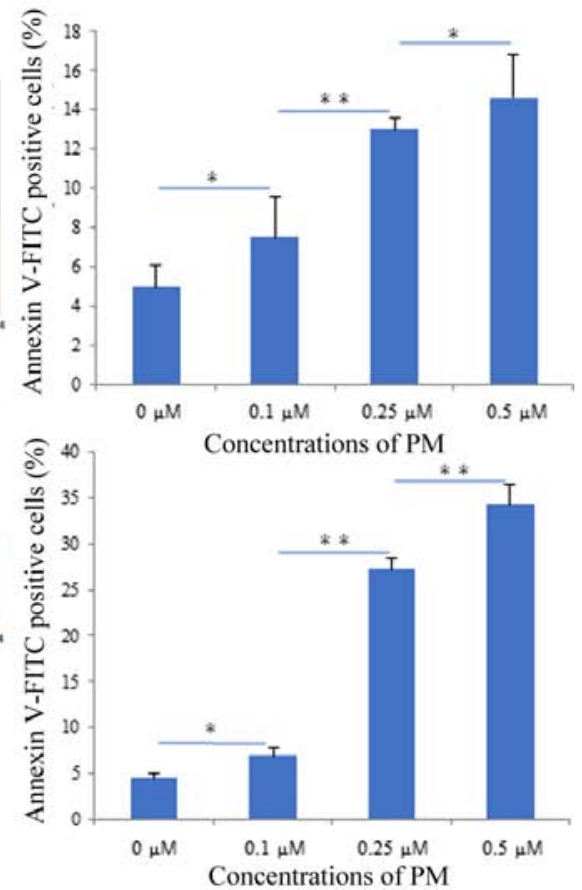

D

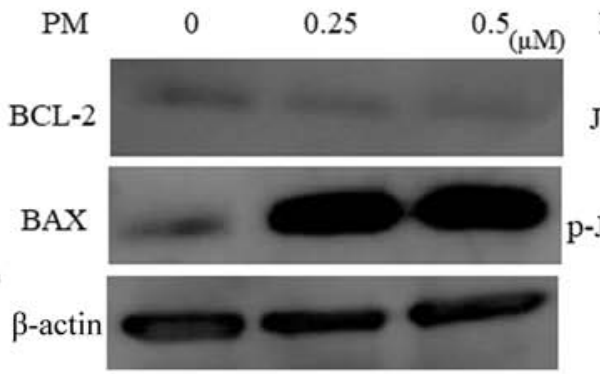

PM 0

0.25

0.5 $(\mu \mathrm{M})$

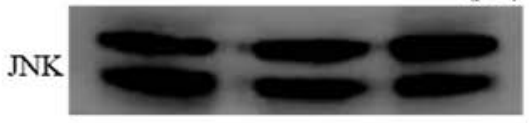

p-JNK

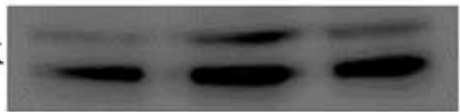

Figure 2. PM induces apoptosis in fibrosarcoma cells. HT1080 cells were treated with various doses (0-1 $\mu \mathrm{M})$ of PM, after which flow cytometry was performed and the percentage of apoptotic cells was calculated at (A) 24 and (B) 48 h. Apoptosis was determined by Annexin V-FITC/propidium iodide double staining using flow cytometry. (C) Effect of PM administration on caspase-3 activity in HT1080 cells. Caspase-3 activity was measured using a Caspase-Glo assay kit and the relative ratios are presented. Caspase- 3 activity was measured after $6 \mathrm{~h}$ of PM treatment. (D) HT1080 cells were treated with PM at concentrations of $0,0.25$ and $0.5 \mu \mathrm{M}$ for $6 \mathrm{~h}$. Western blot analysis was performed using antibodies against Bcl-2, Bax, JNK and phospho-JNK. $\beta$-actin was used as the loading control. Data are expressed as the mean \pm standard deviation $(n=4)$. ${ }^{*} \mathrm{P}<0.05$ and ${ }^{* *} \mathrm{P}<0.01$, as indicated. $\mathrm{PM}$, pristimerin.

of a novel drug is urgently needed. In recent years, drugs derived from natural organic compounds have been used clinically and are gaining attention. PM, a drug extracted from plants, is a natural organic compound, and is reported to have anti-inflammatory and anti-tumor effects (14-18).

PM has been reported to have anti-tumor effects on human breast and lung cancer cells (21). We have previously shown that PM has an anti-tumor effect on human osteosarcomas (22). In the present study, PM exhibited a concentration- and time-dependent inhibition of cell viability in human fibrosarcoma cells. In particular, at concentrations $\leq 0.25 \mu \mathrm{M}$, PM treatment reduced the viability of human fibrosarcoma cells by $>50 \%$, but did not affect the cell viability of normal human fibroblasts. Wu et al, reported that the IC50 values for human breast cancer cell lines, MCF-10A and MDA-MB-231, were 1.4-1.6 and 0.5-0.6 $\mu \mathrm{M}$, respectively, after $24 \mathrm{~h}$ of PM administration and 1.0-1.2 and 0.4-0.6 $\mu \mathrm{M}$, respectively, at $48 \mathrm{~h}$. Wu et al, also reported that the IC50 values for human lung epithelial carcinoma cells, A549 and human liver cancer cell lines, HepG2 and Hep3B, were 0.4-0.6 $\mu \mathrm{M}$ at $72 \mathrm{~h}$ of PM administration (21). Mori et al, reported that the IC50 value for human osteosarcoma cell lines, MNNG and 143B, were 0.8-0.9 and 0.5-0.6 $\mu \mathrm{M}$, respectively, at $24 \mathrm{~h}$ of PM administration, and 0.3-0.4 and 0.3-0.4 $\mu \mathrm{M}$, respectively, at $48 \mathrm{~h}$. Meanwhile, the IC50 values for human osteoblasts were reported to be $\geq 0.5 \mu \mathrm{M}$, at both 24 and $48 \mathrm{~h}$ of PM administration (22). In this study, The IC50 values for human fibrosarcoma cells were $0.16 \mu \mathrm{M}$ at $24 \mathrm{~h}$ of PM administration, and $0.13 \mu \mathrm{M}$ at $48 \mathrm{~h}$ of PM administration, whereas the IC50 values for human fibroblasts were $0.59 \mu \mathrm{M}$ at $24 \mathrm{~h}$ of PM administration, and $0.32 \mu \mathrm{M}$ at $48 \mathrm{~h}$ post PM administration. The IC50 of PM for human fibrosarcoma cells was significantly lower than that for human fibroblasts and human carcinoma cells; hence PM was believed to have high sensitivity for human sarcoma cells.

Cell viability is regulated mainly by apoptosis and proliferation (23). Apoptosis is a form of programmed cell death that primarily occurs to preserve the homeostasis of the individual (24). PM is reported to have an anti-tumor effect, since it induces apoptosis in human osteosarcoma and other carcinomas, such as colorectal cancer, ovarian cancer, and leukemia $(15,21,22,25-27)$. Apoptosis is marked by structural changes in the cell membrane, with progressive 


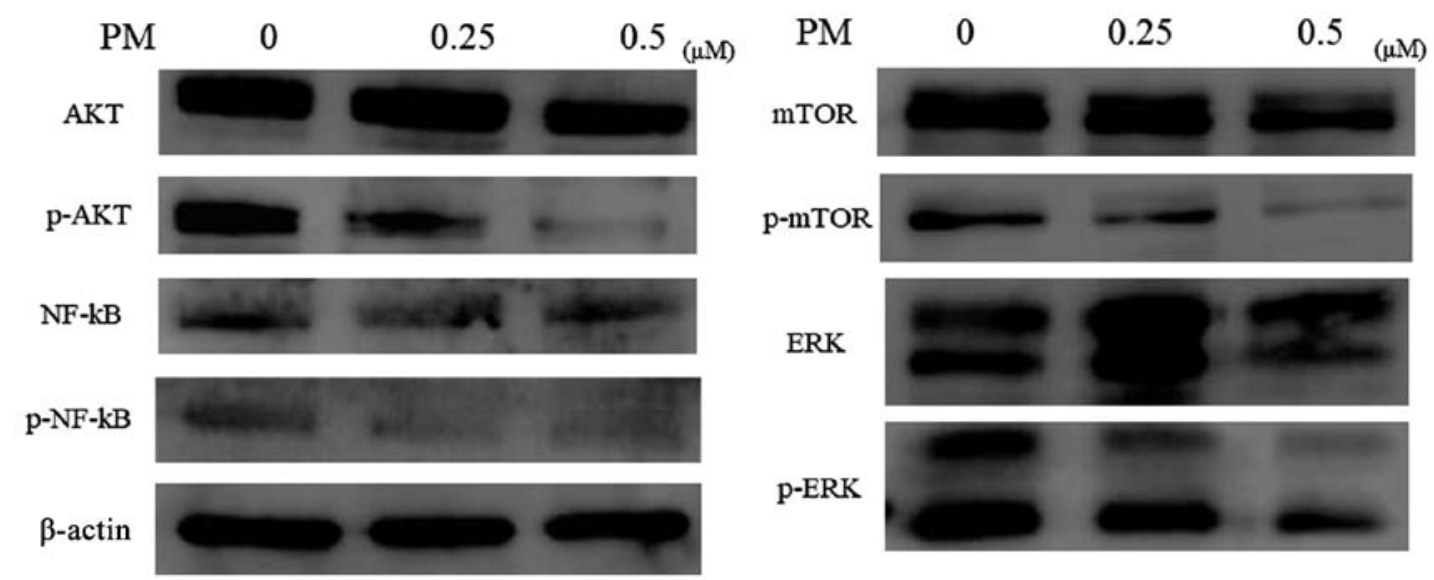

Figure 3. PM inhibits Akt and MAPK signaling. HT1080 cells were treated with PM at concentrations of $0,0.25$ and $0.5 \mu \mathrm{M}$ for $24 \mathrm{~h}$. Western blot analysis was performed using antibodies against phospho-Akt, total Akt, phospho-NF- $\mathrm{B}$, total NF- $\mathrm{B}$, phospho-mTOR, total mTOR, phospho-ERK and total ERK. $\beta$-actin was used as the loading control. PM, pristimerin.
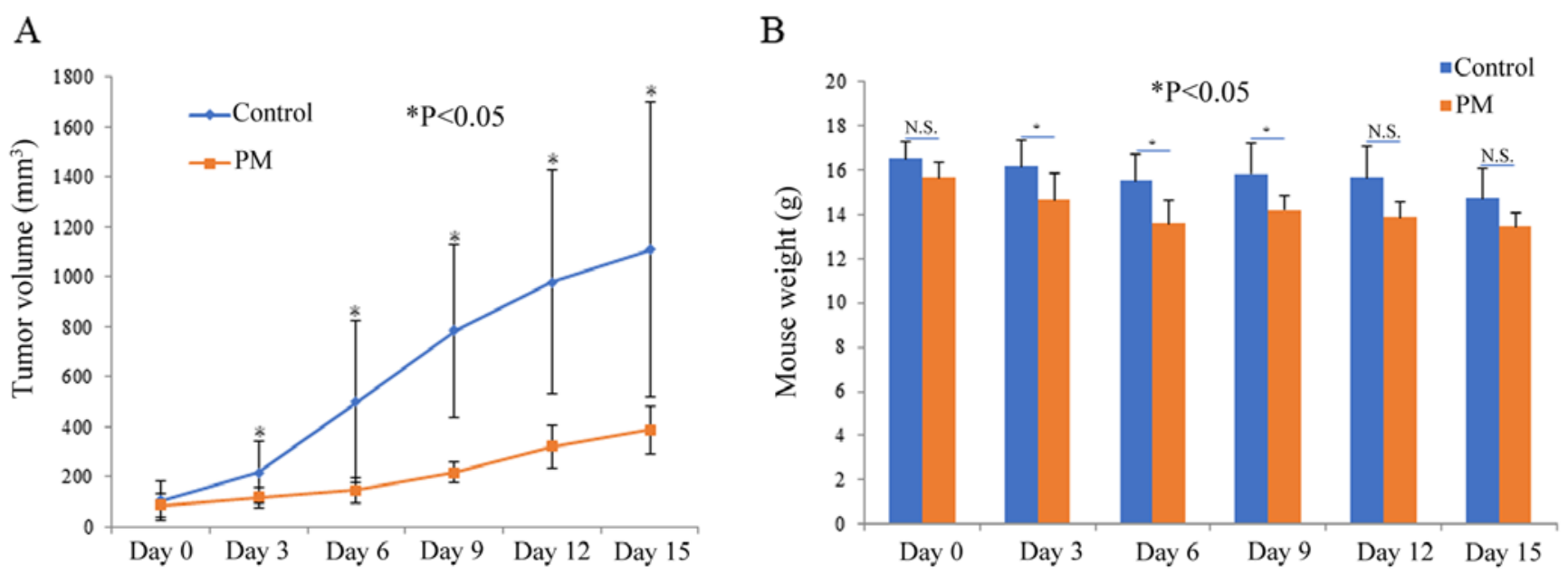

$\mathrm{C}$
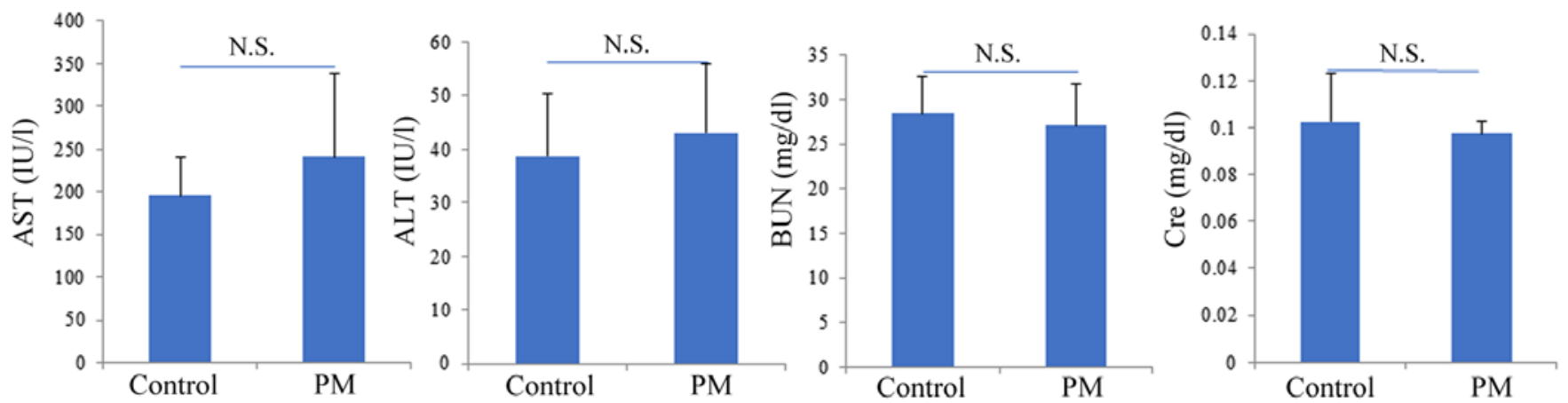

Figure 4. PM suppressed tumor growth and exerted no apparent effect on the living bodies of xenografted mice. PM was administered intraperitoneally every three days once the tumor volume reached $\sim 100 \mathrm{~mm}^{3}$. The (A) tumor volume and (B) weight of mice were subsequently recorded. (C) Blood samples ( $\left.\mathrm{n}=4\right)$ were collected for the assessment of liver and renal toxicity. Data are represented as the mean \pm standard deviation $(\mathrm{n}=4)$. ${ }^{*} \mathrm{P}<0.05$. PM, pristimerin; ALT, alanine aminotransferase; AST, aspartate aminotransferase; BUN, blood urea nitrogen; Cre, creatinine; ns, no significance.

condensation of the nucleus, DNA fragmentation, and changes in cell morphology (28). Structural changes in the cell membrane are mainly detected by Annexin V staining. Annexin $\mathrm{V}$ is cellular protein with strong affinity for phosphatidylserine (PS), which is mainly found on the inner leaflet of the cell membrane in healthy cells. Apoptosis induces structural changes in the symmetry of the cell membrane flipping PS from the inner side of lipid bilayer to the outer side. Hence, Annexin V, which binds to PS, can be used to detect early-stage apoptosis. In the present study, PM treatment caused a concentration-dependent increase in the number of Annexin V-positive human fibrosarcoma cells. In addition, PM administration increased the number of Annexin V-positive cells in a time-dependent 
manner at concentrations of $\geq 0.25 \mu \mathrm{M}$. Therefore, $\mathrm{PM}$ is believed to have an anti-tumor effect by inducing early apoptosis in human fibrosarcoma cells in a concentration- and time-dependent manner. The major pathway by which PM induces apoptosis is via activation of caspases. Pro-apoptosis signals via caspases are divided into initiator caspase group (caspases-2, -8 and -9) and a downstream effector caspase group (caspase-3 and -7), and activation of the effector caspases adversely affects the cell membrane. In the present study, that activity of caspases was evaluated, with focus on the effector caspase, caspase-3. PM activated caspase- 3 after $6 \mathrm{~h}$ of administration. Docetaxel, which also belongs to the terpenoid family, has been observed to activate caspase-3, $24 \mathrm{~h}$ later after drug administration (29). In the present study, caspase- 3 activity at $6 \mathrm{~h}$ after PM administration was found to be comparable to that of docetaxel, however, PM treatment induced a faster response. While the molecular weight of docetaxel is $808 \mathrm{kDa}$, the molecular weight of PM is $465 \mathrm{kDa}$. PM is believed to initiate apoptosis in a shorter time span than docetaxel, because cell penetration ability is inversely proportional to molecular weight (20).

JNK, BCL-2, and BAX are signaling proteins that are components of the caspase pathway (26). JNK is activated by phosphorylation, which causes the downstream inhibition of BCL-2, which in turn increases the BAX/BCL-2 ratio, and induces apoptosis by acting on caspase-9, an effector of the intrinsic caspase pathway (26). We hypothesize that PM treatment increased the levels of phosphorylated JNK and BAX, and decreased the levels of BCL-2, thereby activating caspase-3 and inducing apoptosis.

Signal transduction pathways related to cell proliferation include the PI3K/AKT/mTOR pathway and MAPK pathways (30-33). In carcinomas and sarcomas, these pathways are closely associated with cell proliferation and anticancer drug resistance. PM has been shown to induce apoptosis in human osteosarcomas and carcinomas, such as colorectal cancer, ovarian cancer, and leukemia, via inhibition of AKT and MAPK signaling $(15,22,25,26,34)$. Phosphorylation of AKT induces the downstream phosphorylation of NF- $\kappa \mathrm{B}$ and mTOR, thereby activating them. mTOR signaling integrates environmental cues, such as growth factors, and nutrition/energy status inside and outside of the cell and increases ribosome production and protein synthesis, thereby, promoting cell growth and proliferation. $\mathrm{NF}-\kappa \mathrm{B}$ is a key transcription factor that regulates the cellular stress response, inflammation response, cancer cell proliferation, and apoptosis resistance (35-39). Therefore, mTOR and NF- $\mathrm{mB}$ are important therapeutic targets of cancer treatment. In the present study, PM produced an anti-tumor effect by decreasing the cellular levels of phosphorylated AKT, NF- $\mathrm{B}$, and mTOR in a concentration-dependent manner. Moreover, MAPK pathway has also been shown to be involved in transcription, cell proliferation, cell mobility, and cell survival $(40,41)$. In particular, phosphorylated ERK acts on cyclin D1, inducing protein synthesis and promoting transcription and cell proliferation (42). In the present study, PM treatment inhibited the phosphorylation of ERK, AKT, and hence MAPK signaling, which suggests that PM administration affects cell proliferation. PM suppressed an increase in tumor volume in vivo. The growth inhibitory effect was equivalent to or better than that of colorectal cancer and breast cancer $(26,43)$. PM treatment is believed to produce anti-tumor effect in vitro and in vivo by inducing apoptosis and inhibiting cell proliferation in human fibrosarcoma cells.

Generally, the biological effects of drugs are mainly evaluated by the presence of anorexia or variation in body weight (44). However, only a few reports have analyzed body weight in mouse models. In the present study, we observed a significant difference in body weight between the PM dose group and the control group mice; hence we conclude that PM exhibits low toxicity.

Liver and kidneys are the major organs involved in drug metabolism pathways. AST, ALT, BUN, and creatine levels are often used to evaluate hepatic and renal function. We have previously reported that PM administration in mice does not decrease hepatic function (22), but we did not study the effects of PM administration on renal function. In the present study, PM treatment did not cause either hepatic or renal dysfunction. In addition, the tumor growth was suppressed to the same level or higher even though the total number of doses was reduced by reducing the number of administrations compared to other carcinomas $(26,43)$. We thought that reducing the total dose of PM could more reliably reduce the side effects of the drug. Therefore, we speculate that PM can be safely administered with few side effects on the body.

In conclusion, PM produced anti-tumor effects by inducing apoptosis in human fibrosarcoma cells via activation of the caspases, and inhibited cell proliferation by inhibiting the AKT and MAPK signaling. Therefore, we conclude that PM is safe and could prove to be an effective treatment drug for fibrosarcoma.

\section{Acknowledgements}

This study was funded by JSPS Grants-In-Aid for Scientific Research JP17K10975 and JP18K09115. The authors would like to thank Dr Masaharu Shin-Ya (Department of Immunology, Kyoto Prefectural University of Medicine, Kyoto, Japan) who helped with the research.

\section{Funding}

The present study was supported by the JSPS KAKENHI (grant nos. 17K10975 and 18K09115).

\section{Availability of data and materials}

The datasets used and/or analyzed during the current study are available from the corresponding author on reasonable request.

\section{Authors' contributions}

TS, RT, ST, NM, YA, OM, TK and DH designed experiments. YM, DH and NM performed the research and acquired data. TS, RT, ST, YA, OM and TK interpreted the data and provided valuable advice on the manuscript. $\mathrm{DH}$ wrote the manuscript. TS, RT, YA, OM and TK proofread the manuscript and revised it critically. All authors read the final manuscript and did a final check of the version to publish. TK agreed to be accountable 
for all aspects of the work in ensuring that questions related to the accuracy or integrity of any part of the work are appropriately investigated and resolved.

\section{Ethics approval and consent to participate}

All in vivo procedures were performed in accordance with the NIH Guide for the Care and Use of Laboratory Animals. The present study using mice was approved The Experimental Animals Committee, Kyoto Prefectural University of Medicine (approval no. M30-528).

\section{Patient consent for publication}

Not applicable.

\section{Competing interests}

The authors declare that they have no competing interests.

\section{References}

1. Yonemori K, Kodaira M, Satoh T, Kudo T, Takahashi S, Nakano K, Ando Y, Shimokata T, Mori J, Inoue K, et al: Phase 1 study of olaratumab plus doxorubicin in Japanese patients with advanced soft-tissue sarcoma. Cancer Sci 109: 3962-3970, 2018.

2. Jain S, Xu R, Prieto VG and Lee P: Molecular classification of soft tissue sarcomas and its clinical applications. Int J Clin Exp Pathol 3: 416-428, 2010

3. Pervaiz N, Colterjohn N, Farrokhyar F, Tozer R, Figueredo A and Ghert M: A systematic meta-analysis of randomized controlled trials of adjuvant chemotherapy for localized resectable soft-tissue sarcoma. Cancer 113: 573-581, 2008.

4. Eilber FR, Giuliano AE, Huth JF and Morton DL: A randomized prospective trial using postoperative adjuvant chemotherapy (adriamycin) in high-grade extremity soft-tissue sarcoma. Am J Clin Oncol 11: 39-45, 1988

5. Bramwell VH, Mouridsen HT, Santoro A, Blackledge G, Somers R, Verwey J, Dombernowsky P, Onsrud M, Thomas D, Sylvester R, et al: Cyclophosphamide versus ifosfamide: Final report of a randomized phase II trial in adult soft tissue sarcomas. Eur J Cancer Clin Oncol 23: 311-321, 1987.

6. Mytilinaiou M, Nikitovic D, Berdiaki A, Papoutsidakis A Papachristou DJ, Tsatsakis A and Tzanakakis GN: IGF-I regulates HT1080 fibrosarcoma cell migration through a syndecan-2/Erk/ezrin signaling axis. Exp Cell Res 361: 9-18, 2017.

7. Ratan R and Patel SR: Chemotherapy for soft tissue sarcoma. Cancer 122: 2952-2960, 2016.

8. Sun Y, Gao LL, Tang MY, Feng BM, Pei YH and Yasukawa K: Triterpenoids from Euphorbia maculata and their anti-inflammatory effects. Molecules 23: E2112, 2018.

9. Patlolla JM and Rao CV: Triterpenoids for cancer prevention and treatment: Current status and future prospects. Curr Pharm Biotechnol 13: 147-155, 2012.

10. Akihisa T, Tokuda H, Ichiishi E, Mukainaka T, Toriumi M, Ukiya M, Yasukawa $\mathrm{K}$ and Nishino $\mathrm{H}$ : Anti-tumor promoting effects of multiflorane-type triterpenoids and cytotoxic activity of karounidiol against human cancer cell lines. Cancer Lett 173 9-14, 2001

11. Banno N,Akihisa T, Yasukawa K, TokudaH,Tabata K,Nakamura Y, Nishimura R, Kimura Y and Suzuki T: Anti-inflammatory activities of the triterpene acids from the resin of Boswellia carteri. J Ethnopharmacol 107: 249-253, 2006.

12. Sassa H, Kogure K, Takaishi Y and Terada H: Structural basis of potent antiperoxidation activity of the triterpene celastrol in mitochondria: Effect of negative membrane surface charge on lipid peroxidation. Free Radic Biol Med 17: 201-207, 1994.

13. Dirsch VM, Kiemer AK, Wagner H and Vollmar AM: The triterpenoid quinonemethide pristimerin inhibits induction of inducible nitric oxide synthase in murine macrophages. Eur J Pharmacol 336: 211-217, 1997.
14. Lee JS, Yoon IS, Lee MS, Cha EY, Thuong PT, Diep TT and Kim JR: Anticancer activity of pristimerin in epidermal growth factor receptor 2-positive SKBR3 human breast cancer cells. Biol Pharm Bull 36: 316-325, 2013.

15. Yang H, Landis-Piwowar KR, Lu D, Yuan P, Li L, Reddy GP, Yuan X and Dou QP: Pristimerin induces apoptosis by targeting the proteasome in prostate cancer cells. J Cell Biochem 103: 234-244, 2008

16. Yan YY, Bai JP, Xie Y, Yu JZ and Ma CG: The triterpenoid pristimerin induces U87 glioma cell apoptosis through reactive oxygen speciesmediated mitochondrial dysfunction. Oncol Lett 5: 242-248, 2013.

17. Byun JY, Kim MJ, Eum DY, Yoon CH, Seo WD, Park KH, Hyun JW, Lee YS, Lee JS, Yoon MY and Lee SJ: Reactive oxygen species-dependent activation of Bax and poly(ADP-ribose) polymerase-1 is required for mitochondrial cell death induced by triterpenoid pristimerin in human cervical cancer cells. Mol Pharmacol 76: 734-744, 2009.

18. Costa PM, Ferreira PM, Bolzani Vda S, Furlan M, de Freitas F ormenton Macedo Dos Santos VA, Corsino J, de Moraes MO, Costa-Lotufo LV, Montenegro RC and Pessoa C: Antiproliferative activity of pristimerin isolated from Maytenus ilicifolia (Celastraceae) in human HL-60 cells. Toxicol In Vitro 22: 854-863, 2008.

19. Okuno S, Edmonson J, Mahoney M, Buckner JC, Frytak S and Galanis E: Phase II trial of gemcitabine in advanced sarcomas. Cancer 94: 3225-3229, 2002.

20. Keller F, Wilms H, Schultze G, Offerman G and Molzahn M: Effect of plasma protein binding, volume of distribution and molecular weight on the fraction of drugs eliminated by hemodialysis. Clin Nephrol 19: 201-205, 1983.

21. Wu CC, Chan ML, Chen WY, Tsai CY, Chang FR and Wu YC: Pristimerin induces caspase-dependent apoptosis in MDA-MB-231 cells via direct effects on mitochondria. Mol Cancer Ther 4: 1277-1285, 2005.

22. Mori Y, Shirai T, Terauchi R, Tsuchida S, Mizoshiri N, Hayashi D, Arai Y, Kishida T, Mazda O and Kubo T: Antitumor effects of pristimerin on human osteosarcoma cells in vitro and in vivo. Onco Targets Ther 10: 5703-5710, 2017.

23. Wong RS: Apoptosis in cancer: From pathogenesis to treatment. J Exp Clin Cancer Res 30: 87, 2011.

24. Wyllie AH, Kerr JF and Currie AR: Cell death: The significance of apoptosis. Int Rev Cytol 68: 251-306, 1980.

25. Lu Z, Jin Y, Chen C, Li J, Cao Q and Pan J: Pristimerin induces apoptosis in imatinib-resistant chronic myelogenous leukemia cells harboring T315I mutation by blocking NF-kappaB signaling and depleting Bcr-Abl. Mol Cancer 9: 112, 2010.

26. Yousef BA, Hassan HM, Guerram M, Hamdi AM, Wang B, Zhang LY and Jiang ZZ: Pristimerin inhibits proliferation, migration and invasion, and induces apoptosis in HCT-116 colorectal cancer cells. Biomed Pharmacother 79: 112-119, 2016.

27. Xie G, Yu X, Liang H, Chen J, Tang X, Wu S and Liao C: Pristimerin overcomes adriamycin resistance in breast cancer cells through suppressing Akt signaling. Oncol Lett 11: 3111-3116, 2016.

28. Murgia M, Pizzo P, Sandoná D, Zanovello P, Rizzuto R and Di Virgilio F: Mitochondrial DNA is not fragmented during apoptosis. J Biol Chem 267: 10939-10941, 1992.

29. Tamaki H, Harashima N, Hiraki M, Arichi N, Nishimura N, Shiina H, Naora K and Harada M: Bcl-2 family inhibition sensitizes human prostate cancer cells to docetaxel and promotes unexpected apoptosis under caspase-9 inhibition. Oncotarget 5: 11399-11412, 2014

30. Polivka J Jr and Janku F: Molecular targets for cancer therapy in the PI3K/AKT/mTOR pathway. Pharmacol Ther 142: 164-175, 2014.

31. Liu P, Cheng H, Roberts TM and Zhao JJ: Targeting the phosphoinositide 3-kinase pathway in cancer. Nat Rev Drug Discov 8: 627-644, 2009.

32. Brown JS and Banerji U: Maximising the potential of AKT inhibitors as anti-cancer treatments. Pharmacol Ther 172: 101-115, 2017.

33. Burris HA III: Overcoming acquired resistance to anticancer therapy: Focus on the PI3K/AKT/mTOR pathway. Cancer Chemother Pharmacol 71: 829-842, 2013.

34. Mu X, Shi W, Sun L, Li H, Jiang Z and Zhang L: Pristimerin, a triterpenoid, inhibits tumor angiogenesis by targeting VEGFR2 activation. Molecules 17: 6854-6868, 2012.

35. Brasier AR: The NF-kappaB regulatory network. Cardiovasc Toxicol 6: 111-130, 2006

36. Coussens LM and Werb Z: Inflammation and cancer. Nature 420: $860-867,2002$ 
37. Connolly JL, Rodgers SE, Clarke P, Ballard DW, Kerr LD, Tyler KL and Dermody TS: Reovirus-induced apoptosis requires activation of transcription factor NF-kappaB. J Virol 74: 2981-2989, 2000.

38. Hu G, Wang X, Han Y and Wang P: Protein arginine methyltransferase 5 promotes bladder cancer growth through inhibiting NF- $\kappa \mathrm{B}$ dependent apoptosis. EXCLI J 17: 1157-1166, 2018.

39. Karin M: Nuclear factor-kappaB in cancer development and progression. Nature 441: 431-436, 2006

40. Potthoff RF and George SL: Flexible phase I clinical trials: Allowing for nonbinary toxicity response and removal of other common limitations. Stat Biopharm Res 1: 213-228, 2009.

41. Roberts PJ and Der CJ: Targeting the Raf-MEK-ERK mitogen-activated protein kinase cascade for the treatment of cancer. Oncogene 26: 3291-3310, 2007.
42. Dhillon AS, Hagan S, Rath O and Kolch W: MAP kinase signalling pathways in cancer. Oncogene 26: 3279-3290, 2007.

43. Cevatemre B, Erkısa M, Aztopal N, Karakas D, Alper P, Tsimplouli C, Sereti E, Dimas K, Armutak EII, Gurevin EG, et al: A promising natural product, pristimerin, results in cytotoxicity against breast cancer stem cells in vitro and xenografts in vivo through apoptosis and an incomplete autopaghy in breast cancer. Pharmacol Res Mar 129: 500-514, 2018.

44. Ravasco P, Monteiro-Grillo I, Vidal PM and Camilo ME: Cancer: Disease and nutrition are key determinants of patients' quality of life. Support Care Cancer 12: 246-252, 2004. 